\title{
Discursos del odio en la esfera pública: ¿hasta dónde debe llegar
} la legislación?

Hate speech in the public sphere: how far should legislation go?

Sarikakis, Katharine

Universität Wien

Katharine.Sarikakis@univie.ac.at

Seoane Pérez, Francisco

Universidad Carlos III de Madrid (UC3M)

fseoane@hum.uc3m.es

Forma de citar este artículo:

Sarikakis, K. y Seoane-Pérez, F. (2019). “Discursos del odio en la esfera pública: ¿̇hasta dónde debe llegar la legislación?", RAEIC, Revista de la Asociación Española de Investigación de la Comunicación, vol. 6, núm. 12, 385-393.

\section{Resumen:}

La centralidad de las plataformas digitales en el discurso político ha aumentado la pluralidad de la esfera pública a costa de incrementar también su incivilidad, y en particular el discurso del odio. En este artículo, que sirve de introducción al cuaderno central sobre el 'hate speech', se sitúan los orígenes de la concepción actual sobre el discurso del odio en la posguerra europea. Vista la evolución hacia el extremismo de las democracias contemporáneas, se aboga porque sea el mismo régimen posnacional y 
cosmopolita que surgió de las cenizas de la guerra, el de la Unión Europea, el que proponga una legislación que sirva como estándar internacional y alternativa a la autorregulación de las corporaciones de redes sociales.

Palabras clave: discurso del odio, libertad de expresión, legislación, extremismo.

\section{Abstract:}

The centrality of digital platforms in political discourse has increased the plurality of the public sphere, but at the cost of increasing its incivility, and hate speech in particular. This article, which serves as an introduction to the special section on discourses of hate, places the origins of the current understanding of hate speech in the European postwar period. Given the evolution towards extremism in contemporary democracies, it is argued that the same post-national and cosmopolitan regime that emerged from the ashes of war, the European Union, should be at the forefront of a new legislation that would work as an international benchmark and as an alternative to the self-regulation of social network corporations.

Keywords: hate speech, freedom of speech, legislation, extremism.

\section{EL NUEVO FANTASMA}

Pocas formas menos originales hay de empezar un texto que parafraseando el inicio del Manifiesto Comunista, pero en efecto, en cuanto al discurso del odio se refiere, parece que nos encontramos a ese nuevo fantasma que recorre nuestras esferas públicas, no solo en Europa sino en todo el orbe. El discurso del odio está en todas partes y preocupa a los legisladores y gobernantes porque a menudo es la antesala de violencia contra minorías o el mar de fondo que acaba creando corrientes de estigmatización contra los débiles o los extraños, 'los otros'. Lo vemos en las profanaciones de cementerios judíos en Francia; en los foros de Internet donde los incels, los célibes involuntarios, cargan contra la nueva ola feminista; en los desplazamientos de la minoría Rohingya en Myanmar, azuzados desde Facebook; en las más de 200 amenazas que la senadora 
italiana Liliana Segre, superviviente del Holocausto, recibe a través de las redes sociales. El propio acoso a los mediadores, especialmente a las mujeres periodistas, responde a este inusitado florecer del odio en la esfera pública.

La lista sería muy larga. Incluso se diría que el odio ha traspasado la frontera del otro para colarse en la del conciudadano. Los investigadores hablan cada vez más de la polarización afectiva, el desprecio visceral y emocional del vecino por el simple hecho de apoyar a una formación política distinta (lyengar, Sood y Lelkes, 2012). Cabe preguntarse si este retorno del odio, sin parangón desde los tiempos previos a la Segunda Guerra Mundial, ha regresado ayudado por la desintermediación de las redes sociales. Nuestras esferas públicas serían cada vez menos dependientes de la mediación de las empresas periodísticas tradicionales, dando paso a un ágora de debate más plural pero también más extremista y de fiabilidad dudosa, en la que rumores y discursos inciviles se mezclan con noticias periodísticas en la melée sin fin que son los timelines de las redes sociales. Por no hablar de los mensajes que circulan viralmente a través de los canales de mensajería móviles, en los que el lenguaje del odio llega de la inocente mano de un conocido, incrementando su potencial impacto emocional.

Como muy bien señala el profesor Oscar Pérez de la Fuente en el artículo que abre este número especial sobre los discursos del odio, el hate speech resucita la dialéctica entre dos valores fundamentales: la dignidad humana y la libertad de expresión, la igualdad y la libertad (Pérez, 2019). Tradicionalmente, se ha establecido una distinción entre las aproximaciones europea y americana, en la que el viejo mundo estaría más inclinado hacia la igualdad y la dignidad, mientras que el nuevo mundo priorizaría la libertad. En Estados Unidos, el discurso público solo encontraría freno legal en el caso de incitar explícitamente a la violencia (las consabidas fighting words) o a una acción potencialmente peligrosa para la seguridad de la población (el clásico ejemplo de alarmar sobre un incendio inexistente en un teatro lleno de espectadores).

La difícil distinción entre pensamiento y acción llevó a Calvert (1997) a entender el discurso del odio desde la diferenciación que establecía James Carey (1989) entre comunicación como transmisión y comunicación como cultura. Los legisladores lo tienen 
más fácil cuando el discurso lleva a la acción violenta (el modelo de transmisión) que cuando el discurso crea un entorno favorable a la discriminación o a la aniquilación simbólica (modelo cultural). Que el maltrato físico sea más fácil de probar que el acoso psicológico no implica que este último sea menos pernicioso. Así pues, el discurso del odio es tanto más dañino cuando pasa desapercibido, cuando en lugar de exhibirse en redes sociales alimenta el caldo de cultivo de una discriminación de tipo cultural, solo perceptible como amenaza por las minorías amenazadas.

Es precisamente la conexión entre pensamiento y acción la que ha movido a los legisladores a tratar de prevenir los crímenes de odio mediante el control del discurso del odio. Puesto que, siguiendo el proverbio, el camino hacia el infierno está empedrado de buenas intenciones, no faltan las voces que denuncian el peligro de restringir la libertad de expresión o la legítima controversia pública con la excusa de prevenir la violencia. De hecho, según demuestra Cherian George en su seminal libro Hate spin (George, 2016) los sectores más conservadores de las sociedades a Oriente y Occidente exageran su ofensa frente a discursos críticos con la religión para forzar la aplicación de leyes cada vez más restrictivas con la libertad de expresión. Se daría así la inquietante paradoja de que las legislaciones sobre el discurso del odio contribuyen a subyugar a las minorías que carecen de poder institucional, o a restringir el rango de controversia en la esfera pública.

Por más que los derechos humanos quieran trascender las fronteras políticas y liberar al individuo por la vía de su dignidad universal, los sectores dominantes se apropian de ese ideal cosmopolita particularizándolo, identificando a lo humano con su clase, grupo, etnia o confesión, para a continuación señalar como inhumano o animal a aquél cuya mera existencia es considerada una amenaza para la supremacía de quien detenta el poder.

\section{UN CONCEPTO EN EVOLUCIÓN}

Si aceptamos que una de las vías más rápidas para construir una identidad grupal es la creación de un enemigo, el discurso del odio sería tan viejo como el mundo político. Las leyendas sobre la brutalidad de los españoles en Cuba que con tanta delectación 
propagaba la prensa sensacionalista norteamericana en 1898 serían parte de este alineamiento discursivo que suele preceder a las guerras entre naciones (Companys Monclús, 1998). Pero nuestra concepción contemporánea del discurso del odio es hija del Holocausto y del nuevo orden mundial que siguió a la segunda gran guerra. No es pues casualidad que la definición de hate speech a cargo del Consejo de Europa cite explícitamente al anti-Semitismo y al nacionalismo agresivo como los responsables de la hostilidad hacia las minorías e (in)migrantes.

El Pacto Internacional sobre Derechos Civiles y Políticos de 1966 llama en su Artículo 20 a prohibir la propaganda de guerra y toda defensa de la discriminación nacional, racial o religiosa. Pero también incluye en su Artículo 19 una serie de restricciones al principio general de libertad de expresión, tales como la protección de la seguridad nacional, el orden público o la moralidad. Se abre así una puerta que podría justificar la criminalización de la protesta o el arte transgresor. La Corte Europea de Derechos Humanos, a través de su jurisprudencia, ha sido la encargada de matizar esas disposiciones: el derecho a la libertad de expresión ampararía las críticas e incluso las sátiras religiosas. Así pues, tenemos derecho a que no se nos discrimine por nuestro credo, pero no tenemos derecho a no sentirnos ofendidos por una crítica a nuestro credo.

La Agencia Europea de Derechos Fundamentales incluye las discriminaciones por razones de género en su definición del discurso del odio. En un mundo donde las mujeres ya disputan la primacía de los hombres en el mercado laboral, y donde las expresiones de sexualidad heteronormativas han ganado presencia en la esfera pública, la mitad femenina de la humanidad y las minorías LGTBI se han convertido en el objetivo favorito de expresiones que pretenden mantener a toda costa la tradicional polaridad (asimétrica) entre sexos. 


\section{EL PAPEL DE LAS REDES SOCIALES}

Así como la imprenta se convirtió, a decir de McLuhan, en la arquitecta de un nacionalismo protestante que derrocó el dominio continental del catolicismo romano (McLuhan, 1964), las redes sociales podrían entenderse como una tecnología comunicativa hecha a medida de los movimientos insurgentes y extremistas. Al mismo tiempo, así como la imprenta facilitó el gobierno a distancia y el centralismo del Estadonación, Internet también podría favorecer, de manera paradójica, un mayor control por parte de los estados o las propias compañías tecnológicas, cuyas marcas (Facebook, Twitter) se han convertido en los nuevos grandes mediadores del discurso público.

Puesto que las redes sociales han reemplazado a los medios periodísticos como las principales plataformas de acceso a la información política, su propia definición del discurso del odio y sus políticas para prevenirlo tienen una importancia fundamental a la hora de regular la civilidad del discurso público en nuestras democracias. Facebook define como hate speech el contenido que ataca directamente a los individuos por razones de raza, etnicidad, origen nacional, filiación religiosa, orientación sexual, identidad de género, discapacidades y enfermedades. Quedarían fuera de su definición el humor de mal gusto. Twitter no tiene una política explícita sobre discurso de odio, pero sí sobre comportamientos de odio (hateful conduct), bebiendo así de la tradición estadounidense que previene sobre llamadas explícitas a la violencia por razones análogas a las de Facebook, a las que se añade la discriminación por edad.

Quizá el caso más llamativo de utilización de redes sociales para promover el discurso del odio se dio en Myanmar, donde Facebook fue el medio de difusión de un discurso deshumanizante hacia la minoría Rohingya. Hasta 650.000 refugiados pertenecientes a esta comunidad musulmana fueron perseguidos y obligados a huir a Bangladesh en 2017 (Safi, 2018, 3 de abril). En los países en vías de desarrollo, Facebook es la principal y a veces única vía de información en Internet, ya que los operadores ofrecen acceso a esta red social sin coste por tráfico de datos. A pesar de su posición dominante, Facebook ignoró las denuncias sobre discursos del odio que precedieron a la limpieza étnica de los 
Rohingya. Las promesas de una revisión computerizada más sofisticada, asistida por humanos, no han sido convincentes.

\section{EL DESAFÍO DE LA REGULACIÓN}

Vistas las dificultades de llegar a un estándar de regulación que respete el difícil equilibrio entre dignidad humana y libertad de expresión, ¿̇hasta dónde debe llegar la legislación? ¿Podemos confiar en la autorregulación de las propias plataformas digitales? ¿O debemos imitar la línea dura alemana, que en 2017 aprobó una ley que obliga a las plataformas a eliminar contenido ilegal so pena de cuantiosas multas? La respuesta a este dilema no es fácil. Si nos dejamos llevar por la tentación de la vía alemana, corremos el riesgo de incurrir en la espiral de odio a la que alude Cherian George. Según The Guardian Weekly (Tisdall, 2019, 15 de noviembre), hasta 13 países han seguido el ejemplo germánico, haciendo de la capa un sayo y dando cobertura legal a la censura digital.

La crisis de Facebook por su involuntaria complicidad en el genocidio Rohingya llaman a una acción inmediata. Sin embargo, el contexto donde se aprueba y aplica la legislación marca la diferencia entre una ley polémica y una ley censora, restrictiva en exceso de la libertad de expresión. Curiosamente, el alcance casi universal de estas plataformas digitales hace que sus políticas de autorregulación sean lo más aproximado a una legislación transnacional. El peligro es que quien impone ese estándar no es una democracia avanzada, sino una corporación capitalista cuyo modelo de negocio depende en gran medida de sus incursiones en nuestra privacidad. No es casualidad que un régimen como el chino impida la presencia de este tipo de plataformas en su territorio: las considera dignas rivales en su control panóptico de la población.

El régimen político más cercano al ideal cosmopolita es la Unión Europea. Nuestras esperanzas, pues, están puestas en su Parlamento. Así como Bruselas se ha convertido en el definidor de estándares industriales que acaban siendo imitados allende el continente, es de esperar que el nuevo estándar de legislación sobre privacidad y 
prevención de los crímenes de odio se perfile en el mismo escenario que, tras las atrocidades de la Segunda Guerra Mundial, alumbró un sueño de convivencia que supo mantener y dar vigor a la legítima discrepancia.

Agradecemos a los editores de la Revista de la Asociación Española de Investigación en Comunicación la oportunidad de coordinar este número especial sobre los discursos del odio, que incluye, en consonancia con la vocación iberoamericana de la publicación, contribuciones de colegas españoles, argentinos, venezolanos y brasileños. Este número especial es también el fruto más visible de una Cátedra de Excelencia UC3M-Santander, que en su modalidad recíproca nos permitió intercambiar nuestros campus en Madrid y Viena durante el curso académico 2017-2018 para reflexionar sobre la dimensión política y comunicativa del hate speech. Un debate que, lejos de agotarse en el presente número, continuará en las esferas pública, legal y académica. Por la parte que nos toca, gracias a esa Cátedra una nueva generación de investigadores seguirá diseñando nuevas preguntas y abordando nuevos enfoques a través de tesis doctorales en nuestros respectivos campus. El mismo ímpetu esperamos que impregne a los lectores de este número especial. Tras la gran recesión que arrancó en 2008, casi no existe un ciclo electoral que no contemple la dimensión del discurso del odio y sostenga la perennidad del debate entre libertad de expresión y dignidad humana.

\section{REFERENCIAS BIBLIOGRÁFICAS}

Calvert, C. (1997). Hate speech and its harms: a communication theory perspective. Journal of Communication, 47(1), 4-19.

Carey, J. W. (1989). Communication as culture: Essays on media and society. Nueva York: Routledge.

Companys Monclús, J. (1998). La prensa amarilla norteamericana en 1898. Madrid: Sílex.

George, C. (2016). Hate spin: The manufacture of religious offence and its threat to democracy. Cambridge (Massachusetts): The MIT Press. 
Iyengar, S., Sood, G. y Lelkes, Y. (2012). Affect, not ideology: A social identity perspective on polarization. Public Opinion Quarterly, 76(3), 405-431.

McLuhan, M. (1964). Understanding media: The extensions of man. Nueva York: McGraw Hill.

Pérez, O. (2019). Libertad de expresión y lenguaje del odio como un dilema entre libertad e igualdad. RAEIC, Revista de la Asociación Española de Investigación de la Comunicación, 6(12), 5-34.

Safi, M. (2018, 3 de abril). "Revealed: Facebook hate speech exploded in Myanmar during Rohingya crisis". The Guardian [en línea]. Recuperado el 10 de noviembre de 2019 de https://www.theguardian.com/world/2018/apr/03/revealed-facebook-hatespeech-exploded-in-myanmar-during-rohingya-crisis

Tisdall, S. (2019, 15 de noviembre). "Electoral dysfunction", The Guardian Weekly, vol. 201, núm. 23, 10-11. 